\title{
Agmatine modulates spontaneous activity in neurons of the rat medial habenular complex - a relevant mechanism in the pathophysiology and treatment of depression?
}

\author{
Torsten Weiss ${ }^{1}$, René Bernard ${ }^{2}$, Hans-Gert Bernstein ${ }^{3}$, Rüdiger W. Veh ${ }^{1}$ and Gregor Laube ${ }^{1}$
}

\begin{abstract}
The dorsal diencephalic conduction system connects limbic forebrain structures to monaminergic mesencephalic nuclei via a distinct relay station, the habenular complexes. Both habenular nuclei, the lateral as well as the medial nucleus, are considered to play a prominent role in mental disorders like major depression. Herein, we investigate the effect of the polyamine agmatine on the electrical activity of neurons within the medial habenula in rat. We present evidence that agmatine strongly decreases spontaneous action potential firing of medial habenular neurons by activating 11-type imidazoline receptors. Additionally, we compare the expression patterns of agmatinase, an enzyme capable of inactivating agmatine, in rat and human habenula. In the medial habenula of both species, agmatinase is similarly distributed and observed in neurons and, in particular, in distinct neuropil areas. The putative relevance of these findings in the context of depression is discussed. It is concluded that increased activity of the agmatinergic system in the medial habenula may strengthen midbrain dopaminergic activity. Consequently, the

habenular-interpeduncular axis may be dysregulated in patients with major depression.
\end{abstract}

\section{Introduction}

In the vertebrate brain, the medial habenular complex $(\mathrm{MHb})$, together with the lateral habenular complex $(\mathrm{LHb})$, is part of the epithalamus, an evolutionarily conserved brain region that is originally involved in the circadian regulation of biological rhythms ${ }^{1}$. During mammalian evolution, the habenula acquired additional functions, including in the context of anxiety and stress behavior, learning and memory, attention, and reward

\footnotetext{
Correspondence: Torsten Weiss (torsten.weiss@charite.de)

${ }^{1}$ Charité - Universitätsmedizin Berlin, corporate member of Freie Universität Berlin, Humboldt-Universität zu Berlin, and Berlin Institute of Health, Institute of Vegetative Anatomy, Berlin, Germany

${ }^{2}$ Charité - Universitätsmedizin Berlin, corporate member of Freie Universität Berlin, Humboldt-Universität zu Berlin, and Berlin Institute of Health, Klinik für Neurologie, Department of Experimental Neurology, Berlin, Germany

Full list of author information is available at the end of the article.
}

processing $^{2-4}$. Thus, the habenula serves an integral part in the flow and processing of information from the socalled "limbic forebrain" to the midbrain $^{5,6}$, thereby simultaneously influencing serotoninergic, dopaminergic, and cholinergic neurotransmitter systems. With respect to the morphology of afferent and efferent connections, however, the medial and lateral habenulae represent distinct entities ${ }^{7}$. The two nuclei are uni-directionally connected by axons originating in the $\mathrm{MHb}$ and projecting to the $\mathrm{LHb}^{8}$. The main input to the $\mathrm{MHb}$ via the stria medullaris arises from the triangular septal nucleus and septofimbral nucleus ${ }^{6,9}$. The predominant efferent projection of the $\mathrm{MHb}$ via the fasciculus retroflexus terminates in the interpeduncular nucleus $(\mathrm{K}, \mathrm{L}),(\mathrm{IPN})^{5,9}$. The IPN, in turn, gives rise to ascending projections to limbic structures as well as descending projections to midbrain 
raphe nuclei, central gray, and dorsal tegmental nuclei ${ }^{10}$. Based on morphology, protein and mRNA expression, five subcomponents, namely the superior, inferior, central, lateral, and commissural subnuclei, have been initially described in the $\mathrm{MHb}^{7,11}$. More recently, the MHb has been conceived of as being subdivided into a dorsal component, essentially containing superior and dorsal subnuclei, and a ventral component, containing central, lateral, and medial subnuclei ${ }^{12,13}$. The different subnuclei project to different subdivisions of the IPN in a topographic manner ${ }^{12,14}$. Accordingly, the ventral IPN subnuclei (IPC and IPI) are selectively innervated by the medial part of the MHb, whereas the dorsal group of IP subnuclei is mainly innervated by the central and lateral MHb subnuclei ${ }^{12}$.

The MHb subnuclei use different combinations of neurotransmitter systems ${ }^{11}$. The superior part is glutamatergic and contains neurokinins, the dorsal part of the central $\mathrm{MHb}$ utilizes glutamate and substance $\mathrm{P}$, while the ventral part of the central $\mathrm{MHb}$ as well as the inferior and lateral $\mathrm{MHb}$ are both cholinergic and glutamatergic. Furthermore, the MHb contains high concentrations of nicotinic acetylcholine receptors ${ }^{15}$ as well as $G_{A B A}$ receptors ${ }^{16,17}$, the latter indicating the presence of strong GABAergic inputs 9 . The MHb-IPN axis is part of addiction pathways, most notably with participation in nicotine withdrawal and anxiety ${ }^{18,19}$.

With respect to dendritic and axonal morphology of MHb neurons, several different cell types have been described $^{8}$. Despite their morphological differences, all $\mathrm{MHb}$ cells recorded in the aforementioned study shared the same electrical property, namely spontaneous tonic firing of action potentials at $1-10 \mathrm{~Hz}$, which persisted after blocking of ionotropic glutamate and $\mathrm{GABA}_{\mathrm{A}} / \mathrm{GABA}_{\mathrm{B}}$ receptors. Without blocking synaptic transmission, massive AMPA/ kainate receptor-mediated spontaneous excitatory postsynaptic potentials (EPSPs), most likely generated by neighboring $\mathrm{MHb}$ cells, were also evident, indicating the release of glutamate from at least a subpopulation of $\mathrm{MHb}$ neurons. According to a more recent study, cholinergic neurons account for the spontaneous action potential firing, whereas peptidergic neurons behave differently ${ }^{20}$. The temporal pattern of $\mathrm{MHb}$ cell firing can be modulated by a dual GABAergic synaptic response ${ }^{21}$. In contrast to the typical GABAergic inhibition, in the $\mathrm{MHb}$ there is a $\mathrm{GABA}_{\mathrm{A}}$ receptor-mediated fast excitation ${ }^{21,22}$. It is followed by a slow inhibition due to $G_{A B A_{B}}$ receptor activation as observed in rats at postnatal days 18-25. The GABAergic synaptic input is apparently exclusively extrinsic, because GABA-containing terminals, but neither GABA- nor GADcontaining cell bodies, were observed in the MHb (ref. ${ }^{23}$; own unpublished observation).

In the rat brain, agmatinase, an enzyme responsible for the inactivation of the putative neurotransmitter/ neuromodulator agmatine (recently reviewed in ref. ${ }^{24}$ ), is prominently expressed in the $\mathrm{MHb}$ and the triangular septum $^{25}$. Additionally, the expression of agmatinase is significantly upregulated in the $\mathrm{MHb}$ of depressed patients $^{26}$ ( $\rightarrow$ link to article). These observations led us to hypothesize, that the agmatinergic system may be a part of the information processing in the septal-habenular-interpeduncular axis. This postulation is supported by several further lines of evidence. Agmatine as well as the habenular systems are involved in depression $^{27-31}$ and anxiety ${ }^{18,32-35}$. Although to date the $\mathrm{LHb}$ rather than the MHb has been discussed in the context of depression, there is accumulating evidence for an involvement for the MHb. Furthermore both, the LHb and the $\mathrm{MHb}$, display structural abnormalities with respect to reduced volumes in patients suffering from affective disorders when compared to controls or patients with schizophrenia ${ }^{36}$. In contrast to the mainstream cortical theory of mood disorders ${ }^{37}$, a recent commentary by Loonen and Ivanova attempted to integrate the putative roles of $\mathrm{LHb}$ and $\mathrm{MHb}$ in depression and anxiety in subcortical forebrain and upper brainstem ${ }^{38}$.

Indeed, quite a number of experimental and clinical reports indicate that the cerebral serotonin system is critically involved in mood regulation. In this context, there is increasing evidence for the involvement of a dysbalanced serotonin system in the pathophysiology of depression $^{39,40}$. Consequently, the question arises whether the involvement in depression is a direct effect of agmatine or rather mediated by the serotonergic system. In this context, Zomkowski et al. reported evidence for serotonin receptor involvement in an agmatine antidepressant likeeffect in mouse ${ }^{41}$. However, Krass and colleagues demonstrated that the antidepressant-like effect of agmatine in the forced swimming test is not mediated by serotonin $^{42}$.

In order to shed more light on the biological function of the agmatinergic system in the MHb, we have investigated the influence of agmatine and relevant imidazoline receptor (I1, I2) antagonists/agonists on spontaneous activity in neurons within the rat $\mathrm{MHb}$. With regard to the roles of the agmatinergic and habenular systems in depression and anxiety, we extended our previous immunocytochemical studies on agmatinase protein expression in rat brain gaining additional insight into agmatinase expression in humans using post-mortem brains. The main goal of the present study was to obtain an electrophysiological evidence for a potential mechanism explaining the involvement of the agmatinergic system with psychiatric disorders, notably major depression. In order to extend our previous evidence for a dysregulation of the agmatinergic system in the MHb of depressed individuals ${ }^{26}$, we herein compared the distribution pattern for agmatinase within the rat and human $\mathrm{MHb}$. 


\section{Materials and methods}

\section{Procedures of electrophysiological experiments Slice preparation}

Brain slices were prepared from 20 to 28 day postpartum (P20-28) male Wistar rats obtained from an institutional breeder (Forschungseinrichtungen für Experimentelle Medizin, Charite-Universitätsmedizin Berlin). Specimens were maintained under controlled temperature $\left(22^{\circ} \mathrm{C}\right)$ and scheduled illumination $(12 \mathrm{~h}$ light/dark cycle) conditions with water and food ad libitum. All experiments were approved by the Regional Animals Ethics Committee (LaGeSo No.T 0127/02) and performed in strict accordance with the European Communities Council directive regarding care and use of animals for experimental procedures. All efforts were made to minimize the number of specimens and animal suffering. The animals were deeply anesthetized with isoflurane and then decapitated. Subsequently, the brains were dissected and transferred into $4{ }^{\circ} \mathrm{C}$ cold artificial cerebrospinal fluid (ACSF; see below). Coronal slices ( $400 \mu \mathrm{m}$ thickness) containing the habenular complex were cut using a vibrating microtome (VT 1000S; Leica Instruments, Nussloch, Germany) and transferred into an interface-type recording chamber continuously perfused at a rate of $2.5-5.0 \mathrm{ml} / \mathrm{min}$ with prewarmed $\left(34^{\circ} \mathrm{C}\right)$ oxygenated ACSF containing in $(\mathrm{mM}): 125 \mathrm{NaCl}, 25$ $\mathrm{NaHCO}_{3}, 2.5 \mathrm{KCl}, 1.25 \mathrm{NaH}_{2} \mathrm{PO}_{4}, 2 \mathrm{CaCl}_{2}, 2 \mathrm{MgCl}_{2}$, and 25 D-glucose, $\mathrm{pH} 7.4$ maintained by saturation with carbogen $\left(95 \% \mathrm{O}_{2} / 5 \% \mathrm{CO}_{2}\right)$. In the ASCF solution used for brain preparation and during slicing, $50 \mathrm{mM}$ sucrose was substituted for $\mathrm{NaCl}$ (to a final concentration of $75 \mathrm{mM}$ ). In addition, this solution contained (in $\mathrm{mM}$ ): $0.1 \mathrm{CaCl}_{2}, 6$ $\mathrm{MgCl}_{2}$, and 3 kynurenic acid (Sigma-Aldrich, now Merck; Merck KGaA, Darmstadt, Germany) to suppress transmission in the neuronal tissue. Before recording, the slices were allowed to recover within the recording solution (normal ACSF) for at least $1 \mathrm{~h}$.

\section{Electrophysiological recordings and data acquisition}

Extracellular recordings were performed with glass micropipettes made from borosilicate glass tubing (outer diameter, $1.5 \mathrm{~mm}$; wall thickness, $0.64 \mathrm{~mm}$; Science Products, Hofheim, Germany) using a Sutter micropipette puller (P-97; Sutter Instruments, Novato, CA, USA). When filled with $0.5 \mathrm{M}$ potassium acetate, pipettes resistances amounted to 5-10 M . Single-unit activity was recorded using EXT-01C amplifiers (NPI Instruments, Tamm, Germany). Extracellular spikes were acquired with a CED 1401 plus interface (Cambridge Electronic Design Limited, Cambridge, UK) controlled by Spike2 software (CED Limited). The signals were digitized at $10 \mathrm{kHz}$ and bandpass filtered at 0.3 and $3 \mathrm{kHz}$ cutoff frequency. Once single-unit activity was achieved, spontaneous firing was monitored over 5-10 min to establish a stable baseline prior to the recording session.

\section{Perfusion compounds (PC)}

Brain slices were perfused with the following PC: agmatine sulfate $(2 \mathrm{mM})$, moxonidine hydrochloride $(100 \mu \mathrm{M})$, efaroxan hydrochloride $(100 \mu \mathrm{M})$, and idazoxan hydrochloride $(100 \mu \mathrm{M})$. All PC were purchased from Sigma-Aldrich (now Merck; Merck KGaA, Darmstadt, Germany). PC-containing solutions were freshly prepared prior to the experiments. They were diluted in ACSF from stock solutions dissolved in distilled water. Bath application was achieved via the perfusion system of the recording chamber.

\section{Data analysis and statistics}

Data analysis was done off-line using Spike2 (CED Limited) and Origin 6.0 (MicroCal, Northampton, MA, USA) software. Frequency histograms, number of spikes per second, mean firing rate, and percentage change from control (baseline) activity were determined for each experimental protocol. Each single-unit was evaluated for an increase or decrease in firing rate by comparing 15-min time intervals of activity (i) before pharmacological treatment (control), (ii) during PC administration, and (iii) after washout. For analysis, the time intervals were subdivided into 3-min bins. Experimental data were normalized to the initial basal firing rate for each singleunit. Basal firing was estimated as the frequency at the 3min interval before treatment and taken as $100 \%$. The PC bin interval containing the maximal change of frequency was reported as drug effect, whereas washout was estimated as the firing frequency within the very last interval of the respective washout phase. All numerical data are reported as mean \pm S.E.M. To evaluate the statistical significance, data were subjected to Student's $t$-test (Origin 6.0 software; Microcal, Northampton, MA, USA). A probability value of $P \leq 0.05$ was considered to be significant.

\section{Histological and immunocytochemical techniques}

All animal experiments were conducted in accordance with the guidelines of the European Communities Council directive $86 / 609 /$ EEC and were approved by the Regional Berlin Animals Ethics Committee (LaGeSo No. G 0168/ 01). For immunocytochemistry, adult male Wistar rats were deeply anesthetized using a mixture of Ketavet (Parke-Davis, now Pfizer, New York, NY, USA) and Domitor (Pfizer). The animals were then perfused transcardially with $0.9 \% \mathrm{NaCl}$ solution for 1 min followed by a fixative composed of $4 \%$ paraformaldehyde, $0.05 \%$ glutaraldehyde, and $0.2 \%$ picric acid for $20 \mathrm{~min}$. For immunofluorescence, $4 \%$ paraformaldehyde only was used as a fixative. Brains were then removed from the skull. Tissue 
was rinsed extensively in $0.1 \mathrm{M}$ phosphate buffer, and then freeze-protected with $1 \mathrm{M}$ sucrose in $0.1 \mathrm{M}$ phosphate buffer. Thereafter, tissue was frozen at $-60^{\circ} \mathrm{C}$ in hexane and stored frozen at $-80{ }^{\circ} \mathrm{C}$ until use. For immunocytochemistry, a total of three rats and 90 frontal sections were analyzed. Immunocytochemical doublelabeling experiments were performed 3-5 times for each combination of antigens.

\section{Preparation of human tissue}

All brains were obtained from pathologists or from medical examination officers, with the full consent of each family and in accordance with the ethics and rules outlined by German law and the local ethics commission of the University of Magdeburg. Brains of four individuals without neurological or psychiatric disorders (two males, 54 and 63 years; two females, 54 and 61 years) were studied. Brains were removed between 9 and $41 \mathrm{~h}$ after death. Tissue preparation was performed as described previously $^{43}$. Briefly, brains were fixed in-toto in $8 \%$ phosphate-buffered formaldehyde ( $\mathrm{pH}$ 7.0) for 2 months. After embedding the brains in Paraplast (McCormick Scientific, St. Louis, MO, USA), serial coronal 20- $\mu$ mthick sections were cut on a microtome and mounted on slides. Every 50th section was stained for morphological orientation (combined Cresyl Violet and myelin staining according to Nissl and Heidenhain-Woelcke).

\section{Immunoperoxidase}

Labeling was performed using standard diaminobenzidine/nickel-immunoperoxidase protocols as described previously ${ }^{44}$. Free-floating sections were treated with $1 \%$ sodium-borohydride in phosphate-buffered saline (PBS) for $15 \mathrm{~min}$, washed with PBS, and incubated in a solution containing $10 \%$ normal goat serum (NGS), $0.3 \%$ Triton X100 , and $0.05 \%$ phenylhydrazine in PBS for $30 \mathrm{~min}$. The characterization of the anti-agmatinase antibody was previously described ${ }^{25}$. It was diluted 1:1000 and 1:250, respectively, in $10 \%$ NGS, $0.3 \%$ Triton X-100 supplemented with $0.1 \%$ sodium azide and $0.01 \%$ thimerosal, and incubated for $36 \mathrm{~h}$ at $8{ }^{\circ} \mathrm{C}$. Likewise, the anticalretinin antibody $(1: 15,000, \mathrm{AB} 1550$, raised in goat; Chemicon, Temecula, CA, USA) was applied.

After washing for $1 \mathrm{~h}$ in PBS and another hour in PBS containing $0.2 \%$ bovine serum albumin (PBS/BSA), the sections were incubated in biotinylated secondary goat anti-rabbit antibody (Vector, 1:2000 in PBS/BSA) for $24 \mathrm{~h}$ at $8{ }^{\circ} \mathrm{C}$. The sections were again washed as described above and further incubated for $6 \mathrm{~h}$ with an avidinbiotinyl-peroxidase-complex (Vector Elite $\mathrm{ABC}$ kit) in PBS/BSA. After the final washing, bound peroxidase was visualized in a solution containing $1.4 \mathrm{mM}$ diaminobenzidine, $10 \mathrm{mM}$ imidazole, $6.6 \mathrm{mM}$ nickel ammonium sulfate, and $0.15 \% \mathrm{H}_{2} \mathrm{O}_{2}$ in $50 \mathrm{mM}$ Tris/ $\mathrm{HCl}$ buffer, $\mathrm{pH}$
7.4. All sections were developed for $15 \mathrm{~min}$. Labeled sections were mounted, dehydrated, and cover-slipped with Entellan.

\section{Immunofluorescence}

The incubation protocol used for immunofluorescence labeling (applies to supplemental figure S2) of rat brain tissue was identical with the immunoperoxidase protocol except for phenylhydrazine which was not used. Also normal donkey serum instead of NGS was used as a blocking reagent. Secondary antibodies used were goat anti-rabbit $\mathrm{CY} 3$, goat anti-mouse $\mathrm{CY} 2$, and donkey antigoat CY2. Labeled sections were mounted on slides, airdried, dipped in xylene, and cover-slipped with DPX. For double-labeling experiments, commercial antibodies against calretinin $^{45,46}(1: 15,000, \mathrm{AB} 1550$, raised in goat; Chemicon, Temecula, CA, USA), parvalbumin ${ }^{47}$ (1:5000, P-3171, raised in mouse; Sigma, St Louis, MO, USA), calbindin $^{48}$ (1:5000, C-8666, raised in mouse; Sigma), were used. For controls, either primary or secondary antibodies were omitted. No labeling was detected under these conditions.

\section{Anterograde tracer injections}

Two adult Wistar rats (264 and $275 \mathrm{~g}$ body weight) were anesthetized with $2-3 \%$ Isoflurane in $100 \% \mathrm{O}_{2}$ and placed in a stereotactic frame (David Kopf, Tujunga, CA, USA). An isoflurane- $\mathrm{O}_{2}-$ mix was continuously delivered through a rat anesthesia mask (David Kopf). Core body temperature was monitored and maintained at $37^{\circ} \mathrm{C}$ using a feedback-controlled heating blanket. An access hole was made into the skull to unilaterally aim for the triangular septum according to a rat brain atlas. For the tracer injection, a glass pipette with end opening of $20 \mu \mathrm{m}$ filled with $10 \%$ biotinylated dextran amine (BDA) was lowered into the brain at a $10^{\circ}$ angle according to the following coordinates: Bregma $-0.8 \mathrm{~mm}$; lateral: $+0.6 \mathrm{~mm}$, distance from dura surface: $-4.8 \mathrm{~mm}$. BDA was ionotophoretically injected over $30 \mathrm{~min}$. For pre- and post-injection, the electrode was maintained at position for $5 \mathrm{~min}$. Finally, the pipette was removed from the brain and the scalp was closed with surgical sutures. Anesthesia was discontinued, and after recovery, the rats were transferred to their home cages. Three weeks later, the rats were deeply anesthetized by intraperitoneal injection of a mixture of 45 volume fractions ketamine hydrochloride $(100 \mathrm{mg} / \mathrm{ml}$; DeltaSelect, Pfullingen, Germany), 35 volume fractions xylazine hydrochloride $(20 \mathrm{mg} / \mathrm{ml}$; BayerVital), and 20 volume fraction saline $0.9 \%$. This mixture was dispensed at a dose of $0.16 \mathrm{ml} / 100 \mathrm{~g}$ body weight. In addition, $200 \mathrm{IU}$ heparin sodium (Heparin-Rotexmedica, Trittau, Germany) were administered intraperitoneally to prevent blood clotting during perfusion. Anesthetized rats were transaortically perfused for $10 \mathrm{~s}$ with body-temperature warm plasma 
substitute (Deltadex 60; DeltaSelect), followed by $0.1 \mathrm{M}$ phosphate buffer ( $\mathrm{pH} 7.4$ ) containing $4 \%$ paraformaldehyde, $0.05 \%$ glutaraldehyde, and $0.2 \%$ picric acid for $20 \mathrm{~min}$. After a final 5-min flush of the vasculature with $0.15 \mathrm{M}$ sucrose in $0.1 \mathrm{M}$ phosphate buffer ( $\mathrm{pH} 7.4$ ), the brains were removed, immersed in $0.8 \mathrm{M}$ sucrose overnight for cryoprotection, sagittaly cut into blocks which were shock-frozen in hexane at $-70^{\circ} \mathrm{C}$, and subsequently stored at $-80^{\circ} \mathrm{C}$ until they were serially cut into $25-\mu \mathrm{m}$ thick sections. Thereafter, individual series were processed for light microscopic visualization of BDA. Free floating sections were washed in PBS containing 0.2\% BSA (PBS-A) and $0.3 \%$ Triton, incubated overnight at $4{ }^{\circ} \mathrm{C}$ with peroxidase-labeled streptavidin (NEL 750; PerkinElmer, Rodgau-Jügesheim, Germany) diluted 1:20,000 in PBS-A. Next, sections were rinsed in PBS and pre-incubated in a solution containing $0.05 \% \quad 3,3^{\prime}$-diaminobenzidine and $10 \mathrm{mM}$ imidazole in Tris buffer ( $50 \mathrm{mM}, \mathrm{pH}$ 7.6). Next, ammonium nickel sulfite at $0.3 \%$ was added to the solution. The peroxidase reaction was started by the addition of hydrogen peroxide at a final concentration of $0.0015 \%$. After $10-15 \mathrm{~min}$ under visual control, the reaction was stopped by repeated washes in PBS. Finally, sections were mounted onto gelatin-coated slides, dehydrated in a graded series of alcohol, cleared in xylene, and cover slipped. Digital images (applies to supplemental figure S4) of the slides were taking with an upright Leica DMRB light microscope connected to a high-resolution digital camera (MBF-CX9000; MBF Bioscience, Williston, VT). Images were adjusted for brightness and contrast in Adobe Photoshop CS3 and arranged in Adobe Illustrator CS3.

\section{Retrograde tracer injections}

Two further rats received microinjections aimed for the ventrolateral IPN/parainterfascicular nucleus of the VTA with the retrograde tracer gold-coupled wheatgerm agglutinin (WGA-apoHRP-gold; 15-nm particle size; $10-20 \mu \mathrm{g} / \mathrm{ml}$ in distilled $\mathrm{H}_{2} \mathrm{O}$, pH 7.0-7.5; E-Y Laboratories, San Mateo, CA). Anesthesia, glass capillaries, and animal preparation were identical to the above-described tracer injections with the following stereotactic aim coordinates used: $5.8 \mathrm{~mm}$ posterior to bregma, $0.5 \mathrm{~mm}$ from the midline, and $8.0 \mathrm{~mm}$ ventral to the dura. Careful pressure application was used to inject approximately $0.3 \mu \mathrm{l}$ tracer. The capillary was held in place for an additional $10 \mathrm{~min}$ before retrieving from the brain. After the wounds were closed and anesthesia discontinued, the animals were allowed to recover in their home cage. After 5 days, the animals were sacrificed, their brains were quickly removed, and they were processed for subsequent sectioning as described above (applies to supplemental figure S4). WGA-apoHRP-gold tracer was visualized in the section using a silver enhancement protocol ${ }^{49}$.

\section{Results}

\section{Electrophysiology}

The physiological data presented in this study are based on extracellular single unit recordings obtained from 110 neurons within the $\mathrm{MHb}$ in slice preparations of 30 rats (Fig. 1a). MHb neurons displayed spontaneous discharge of action potentials at a mean firing rate of $9.5 \pm 1.0 \mathrm{~Hz}$ in a range from 1 to $20 \mathrm{~Hz}$. With respect to the pattern of discharge, $\mathrm{MHb}$ neurons both exhibited regular tonic firing of action potentials or repetitively discharged single action potentials randomly distributed (Fig. 1b, left panels). Characteristically, the recorded $\mathrm{MHb}$ neurons generated trains of broad (duration $>3 \mathrm{~ms}$ ), triphasic extracellular spikes (Fig. 1b, right panels).

\section{Agmatine suppresses spontaneous action potential firing in rat $\mathrm{MHb}$ neurons}

To investigate, whether the rat $\mathrm{MHb}$ underlies polyaminergic modulation, we tested the effects of agmatine on the basal firing rate of individual $\mathrm{MHb}$ neurons. Bath application of agmatine $(2 \mathrm{mM})$ markedly suppressed spontaneous action potential firing of $\mathrm{MHb}$ neurons. A typical response is illustrated in Fig. 1c. Here, the discharge of the recorded neuron decreased from 15.1 spikes/s under control conditions to 5.2 spikes/s with agmatine (Fig. 1d). Similar results were obtained in another 12 neurons. In six neurons, agmatine slightly increased action potential firing, whereas in one recorded cell, neuronal activity was not altered. On average, agmatine decreased the mean firing rate of $\mathrm{MHb}$ neurons to $71.1 \pm 5.5 \%$ of control $(P \leq 0.002, n=13$, Fig. $1 \mathrm{e})$. The effect appeared within 1.5-3 min after application of the perfusion compound, reached a maximum at about 10 min after application, and was partially reversible with discharge recovering slowly upon washout within $30 \mathrm{~min}$ to $1.5 \mathrm{~h}$ (Fig. 1f).

\section{Depression of $\mathrm{MHb}$ neuron discharge is mimicked by the imidazoline-receptor agonist moxonidine}

To evaluate the biological relevance of the agmatine action onto spontaneous neuronal activity in rat $\mathrm{MHb}$, we examined the influence of moxonidine, an agonist of endogenous imidazoline receptors. Not otherwise than agmatine, the imidazoline-receptor agonist distinctly suppressed action potential firing of $\mathrm{MHb}$ neurons (Fig. 2a). The quantification of the observed effect for the experiment illustrated in Fig. 2a revealed a decrease of discharge from $4.1 \mathrm{spikes} / \mathrm{s}$ under control conditions to 1.3 spikes/s with moxonidine $(100 \mu \mathrm{M}$, Fig. 2b). Similar results were obtained in another 12 neurons. In three neurons, action potential firing was slightly enhanced. In total, the reduction of mean firing rate with moxonidine amounted to $61.8 \pm 5.3 \%$ of control $(P \leq 0.001, n=13$, Fig. 2c). Although the agmatine-mediated reduction of 

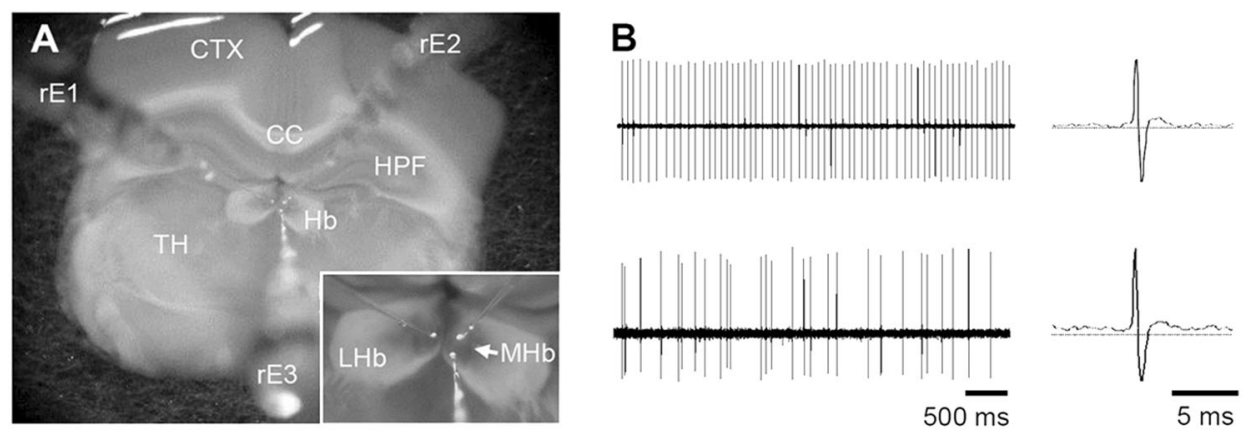

C Control

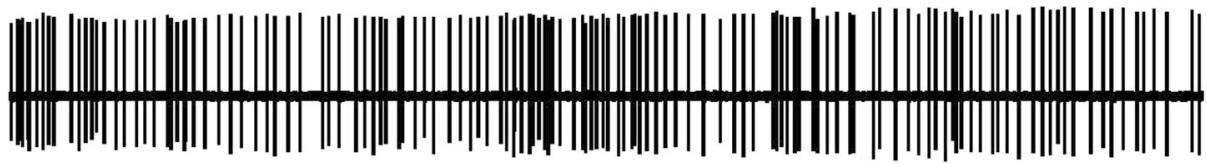

+ $2 \mathrm{mM}$ Agmatine

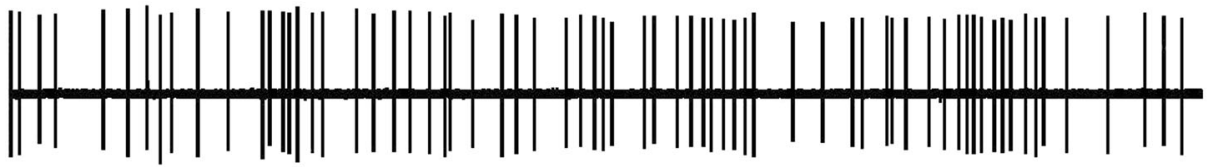

D 20
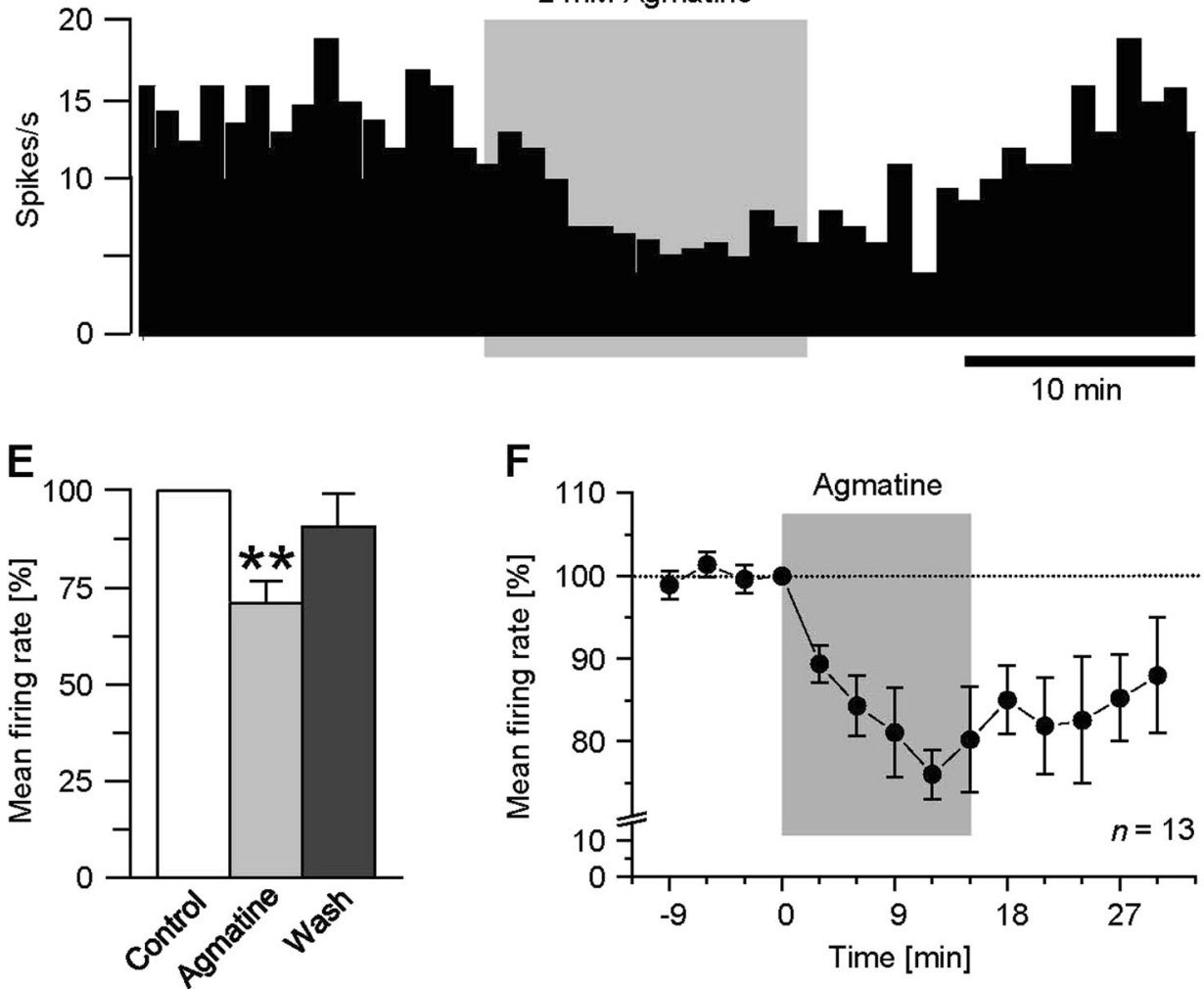

F

$F_{110} \quad$ Agmatine

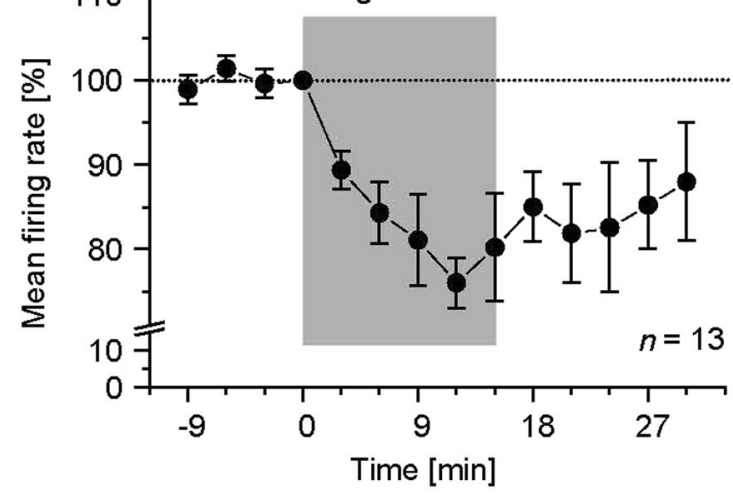

Fig. 1 (See legend on next page.) 
(see figure on previous page)

Fig. 1 Agmatine suppresses spontaneous action potential firing within the rat $\mathbf{M H b}$. a Photomicrograph of a coronal section (400- $\mu \mathrm{m}$ thick) of rat diencephalon comprising the habenular complex. Inset at higher magnification focuses on the arrangement of the recording electrodes for that triple recording. CC corpus callosum, CTX cortex, Hb habenular nucleus, HPF hippocampal formation, LHb lateral habenular complex, MHb medial habenular complex, rE1-3 recording electrodes, TH thalamic nucleus. b Examples of representative extracellular recordings from tonic regular (upper trace) and irregular (lower trace) firing MHb neurons. Expansions of the respective recordings shown at the right illustrate shape and time course of action potentials on enlarged time scales. c Representative recordings from another MHb neuron within a slice under control conditions (top trace) and with bath-applied agmatine (bottom trace). d Rate histogram (bin width $60 \mathrm{~s}$ ) obtained from the experiment shown in $\mathrm{c}$ illustrating the agmatine-induced decrease in spontaneous action potential firing of the neuron. Note the recovering of discharge upon washout. e Bar graph summarizing the quantified data for the agmatine effect. Asterisk indicates a significance level of $\mathrm{P} \leq 0.04(n=13)$. $\mathbf{f}$ Time course response diagram representing the results for the effect of agmatine on discharge frequency of 13 recorded $\mathrm{MHb}$ neurons. Normalized data are plotted as mean firing rate \pm S.E.M. Note the discontinuity of $y$-axis. Gray backgrounds in $b$ and $c$ denote the time frame of agmatine administration

spontaneous discharge was weaker (by approx. $29 \%$ with agmatine vs. $38 \%$ with moxonidine), the two effects were not significantly different $(P=0.14)$. As observed with agmatine, the moxonidine effect emerged within minutes after onset of treatment, reached a maximum at about $10 \mathrm{~min}$ after application, and was partially reversible upon prolonged washout (Fig. 2d).

\section{Suppression of $\mathrm{MHb}$ neuron activity is mediated via I1-like imidazoline receptors}

To elucidate the imidazoline receptor subtype involved in the depression of spontaneous action potential firing in $\mathrm{MHb}$ neurons, we examined the effects of selective antagonists of the imidazoline 1 (I1-like) and imidazoline 2 (I2-like) receptor, respectively.

First, we examined the influence of efaroxan, an inhibitor of the I1-like receptor on both agmatine- and moxonidine-mediated suppression of spontaneous discharge. As illustrated in Fig. 3, pretreatment (15 min) with the I1-antagonist efaroxan $(100 \mu \mathrm{M})$ had no detectable effect on action potential firing of individual $\mathrm{MHb}$ neurons (Fig. 3a, b, middle traces). However, efaroxan strongly counteracted the depressant action of agmatine and moxonidine, respectively. Neither co-application of agmatine nor moxonidine with efaroxan altered $\mathrm{MHb}$ neuron discharge (Fig. 3a, b, lower traces). For the example shown in Fig. 3a, it is obvious from the respective time histogram that the firing rate of the recorded neuron was unchanged amounting to about 15 spikes/s under control, with efaroxan alone as well as with efaroxan and agmatine (Fig. 3c). Thus, efaroxan completely blocked the agmatine effect. Similar effects were observed in another nine $\mathrm{MHb}$ neurons. On average, mean firing rate after coapplication of agmatine with efaroxan was slightly, but not significantly, decreased to $98.4 \pm 2.3 \%$ of control $(P=$ $0.439, n=10$, Fig. 3e), a value which did not differ from that obtained with efaroxan alone $(97.4 \pm 3.7 \%, P=0.55)$ or after washout $(98.6 \pm 1.9 \%, P=0.78)$, respectively.

In the same way, efaroxan blocked the moxonidinemediated suppression of action potential firing of $\mathrm{MHb}$ neurons. In the case of the recorded neuron illustrated in
Fig. 3b, neither pretreatment with the I1-antagonist $(100 \mu \mathrm{M})$ nor subsequent co-application of efaroxan and moxonidine altered spontaneous firing. Here, basal firing rate amounted to 7.3 spikes/s under control conditions, 7.6 spikes/s with efaroxan alone, and 7.3 spikes/s with coapplication of efaroxan and moxonidine (Fig. 3d), indicating a complete inhibition of the moxonidine effect. Similar results were obtained in another eight recordings. On average, mean firing rate of $\mathrm{MHb}$ neurons during simultaneous treatment with efaroxan and moxonidine amounted to $102.3 \pm 7.9 \%$ of control $(n=9$, Fig. $3 f)$. This value did not differ from that obtained with efaroxan alone $(102.0 \pm 3.2 \%$, $P=0.53)$ and after washout $(94.8 \pm 5.2 \%, P=0.084)$.

Secondly, we investigated the effect of idazoxan, an inhibitor of the I2-like receptor on agmatine- and moxonidine-mediated depression of action potential firing of neurons within the rat MHb. As observed for the I1-like antagonist efaroxan, pretreatment of slices with idazoxan $(100 \mu \mathrm{M})$ had no detectable effects on spontaneous discharge of $\mathrm{MHb}$ neurons (Fig. 4a, b, middle traces). However, in contrast to efaroxan, the I2-antagonist did not prevent the suppressive effect of agmatine and moxonidine onto the firing rate of $\mathrm{MHb}$ neurons. Thus, as shown in Fig. 4a (lower trace), co-application of agmatine $(2 \mathrm{mM})$ and idazoxan $(100 \mu \mathrm{M})$ distinctly suppressed spontaneous discharge of individual $\mathrm{MHb}$ neurons. The quantification of the observed effect on the recorded neuron revealed a decrease of firing from 12.5 spikes/s under control conditions to 7.5 spikes/s with the two perfusion compounds (Fig. 4c). Similar results were obtained in another seven recordings. In three recordings, administration of idazoxan and agmatine slightly increased action potential firing. On average, the coapplication of agmatine and idazoxan significantly reduced the mean firing rate to $62.2 \pm 4.6 \%$ of control $(P \leq$ $0.003, n=8$, Fig. 4e), which is not different $(P=0.58)$ from the value observed with agmatine alone $(71.1 \pm 5.5 \%)$.

Likewise, idazoxan failed to block the moxonidine effect on action potential firing of $\mathrm{MHb}$ neurons. A typical response to co-application of moxonidine and idazoxan is 

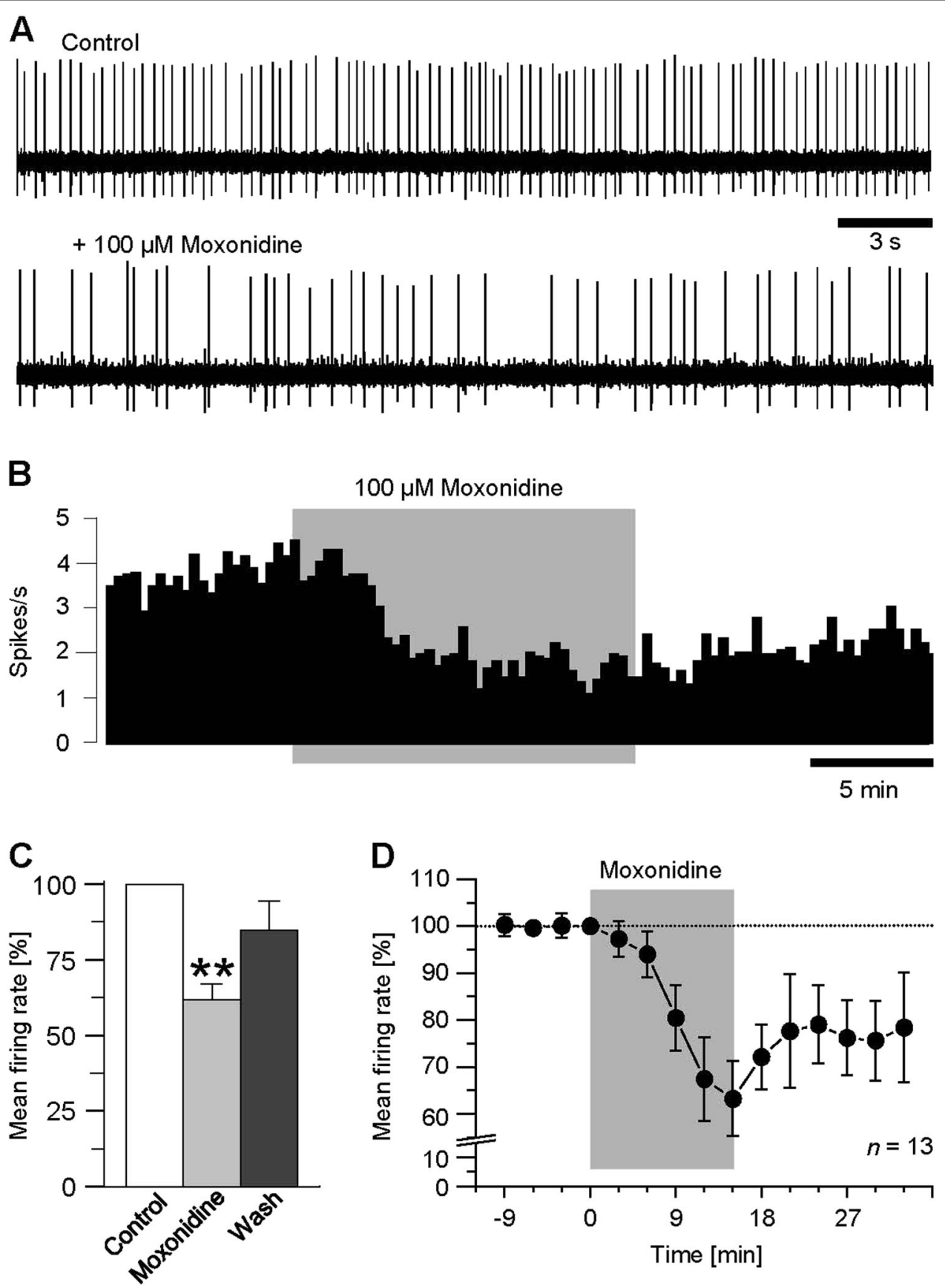

Fig. 2 . Agmatinergic suppression of spontaneous action potential firing in the rat MHb is mimicked by the imidazoline-receptor agonist moxonidine. a Representative recordings from a MHb neuron under control conditions (top trace) and following bath application of moxonidine (lower trace). b Rate histogram (bin width $20 \mathrm{~s}$ ) of the experiment illustrated in a showing the moxonidine-induced decrease of discharge in the recorded neuron. c Bar graph summarizing the results for the moxonidine effect. Asterisks indicate a significance level of $\mathrm{P} \leq 0.01$ ( $n=13$ ). $\mathbf{d}$ Time course response diagram illustrating the effect of moxonidine on $\mathrm{MHb}$ neuron firing obtained from 13 single-unit recordings. Normalized data are plotted as mean firing rate \pm S.E.M. Note the discontinuity of $y$-axis

illustrated in Fig. 4b. In that neuron, the firing rate decreased from 10.3 spikes/s in control to 7.3 spikes/s with idazoxan and moxonidine (Fig. 4d). Similar effects were observed in another eight experiments. In four neurons, action potential firing was slightly enhanced. In total, the reduction of mean firing rate of MHb neurons with moxonidine and idazoxan amounted to $58.0 \pm 9.1 \%$ of control $(P \leq 0.004, n=9$, Fig. $4 \mathrm{f})$. This decline is not different $(P=0.79)$ from that obtained with moxonidine alone $(61.8 \pm 5.3 \%$ of control). 

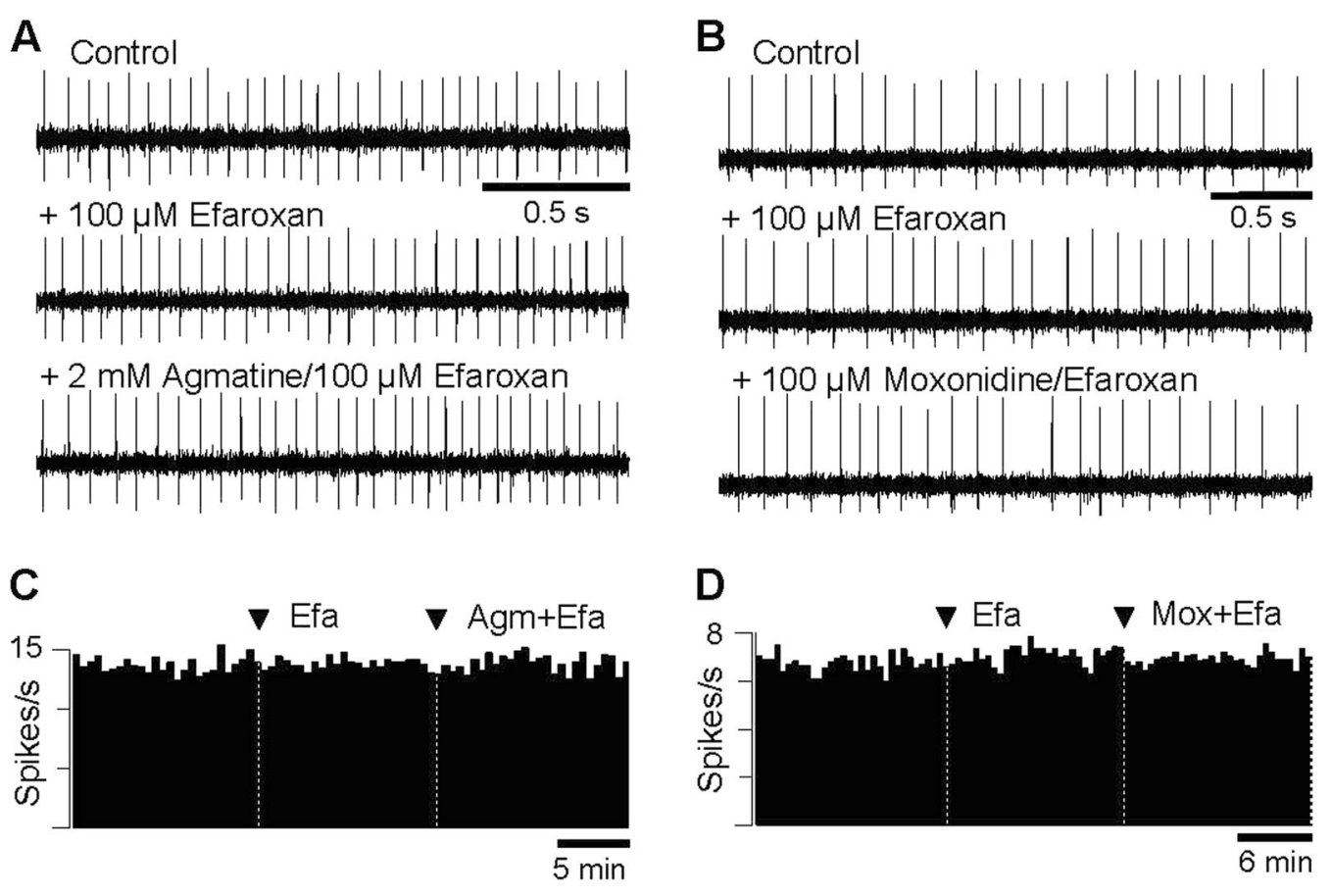

$+100 \mu \mathrm{M}$ Moxonidine/Efaroxan
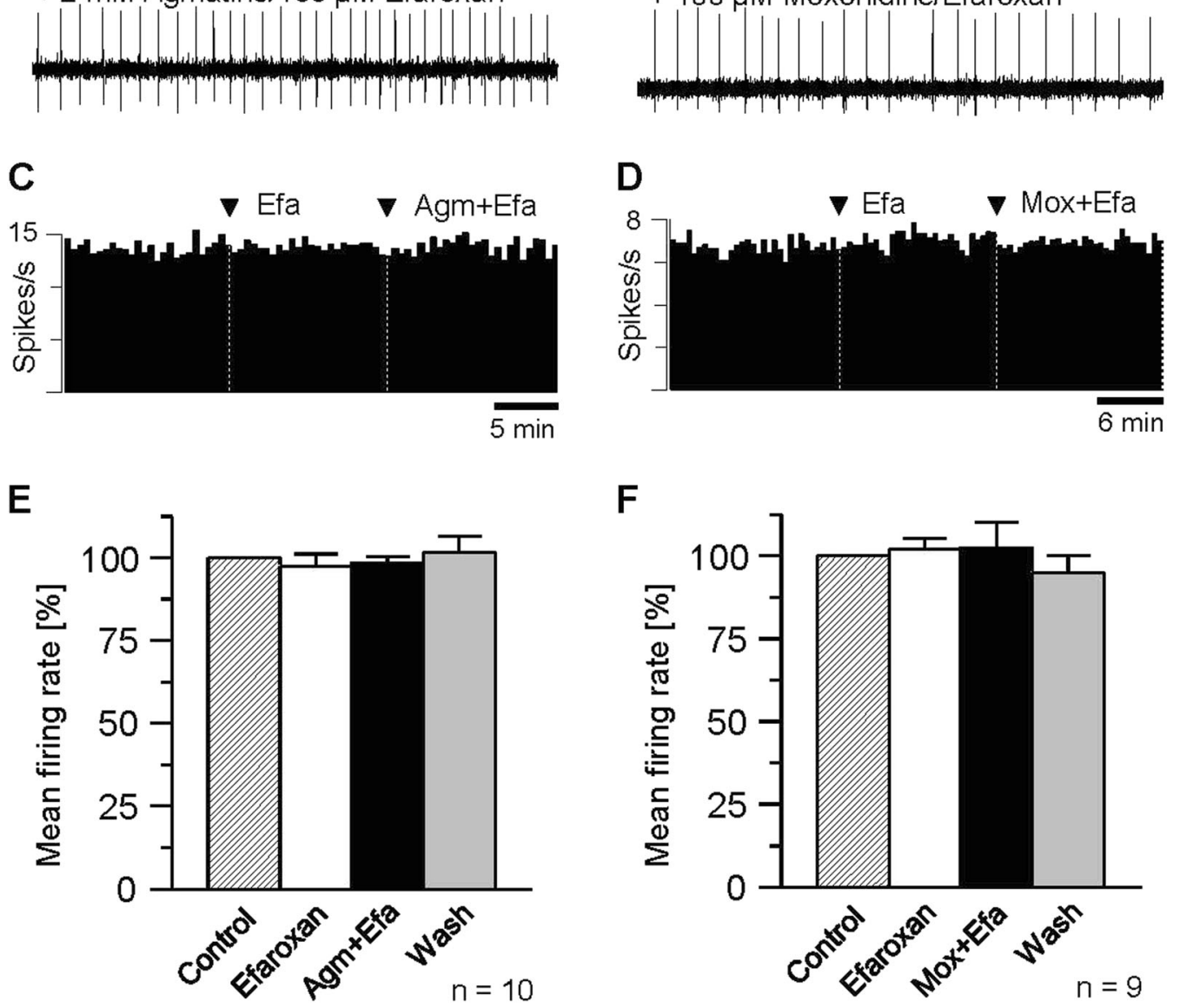

Fig. 3 Agmatine- and moxonidine-mediated suppression of spontaneous discharge of MHb neurons is potently blocked by efaroxan, an I1-subtype imidazoline receptor antagonist. a Representative recordings from a MHb neuron in a slice under control conditions (top trace), following administration of efaroxan (middle trace) and upon efaroxan co-applied with agmatine (bottom trace). b Single-unit recordings from another slice under control conditions (top trace), following administration of efaroxan (middle trace) and upon efaroxan co-applied with moxonidine (bottom trace). $\mathbf{c}$ and $\mathbf{d}$ Rate histograms (bin widths $30 \mathrm{~s}$ ) obtained from the recordings shown $a$ and $b$, illustrating the responses with efaroxan alone and following co-application of the 11-receptor antagonist with agmatine and moxonidine, respectively. Arrow heads indicate the onsets of the respective application of the perfusion compounds. e and $\mathbf{f}$ Bar graphs summarizing the results of the experiments on efaroxan acting indicating a complete inhibition of both agmatine- $(e, n=10)$ and moxonidine- $(f, n=9)$ mediated suppression of action potential firing in the $\mathrm{MHb}$. Normalized data are plotted as mean firing rate \pm S.E.M

There is experimental evidence that beyond acting on imidazoline receptors, agmatine may interact with $\alpha 2$ adrenergic receptor binding $\operatorname{sites}^{50}$. Also the imidazoline receptor antagonists efaroxan and idazoxan have been shown to exert effects on that receptor type ${ }^{51-53}$. Therefore, we performed control experiments using yohimbine, a selective $\alpha 2$-adrenergic antagonist, to elucidate the possible involvement of $\alpha 2$-adrenergic receptors with the agmatinergic depression of action potential firing in the rat MHb. Our preliminary data indicate that an activation of $\alpha 2$-adrenergic receptors, in contrast to imidazoline I1 receptors, may only insignificantly account for the inhibition of action potential discharge induced by agmatine and moxonidine. This 

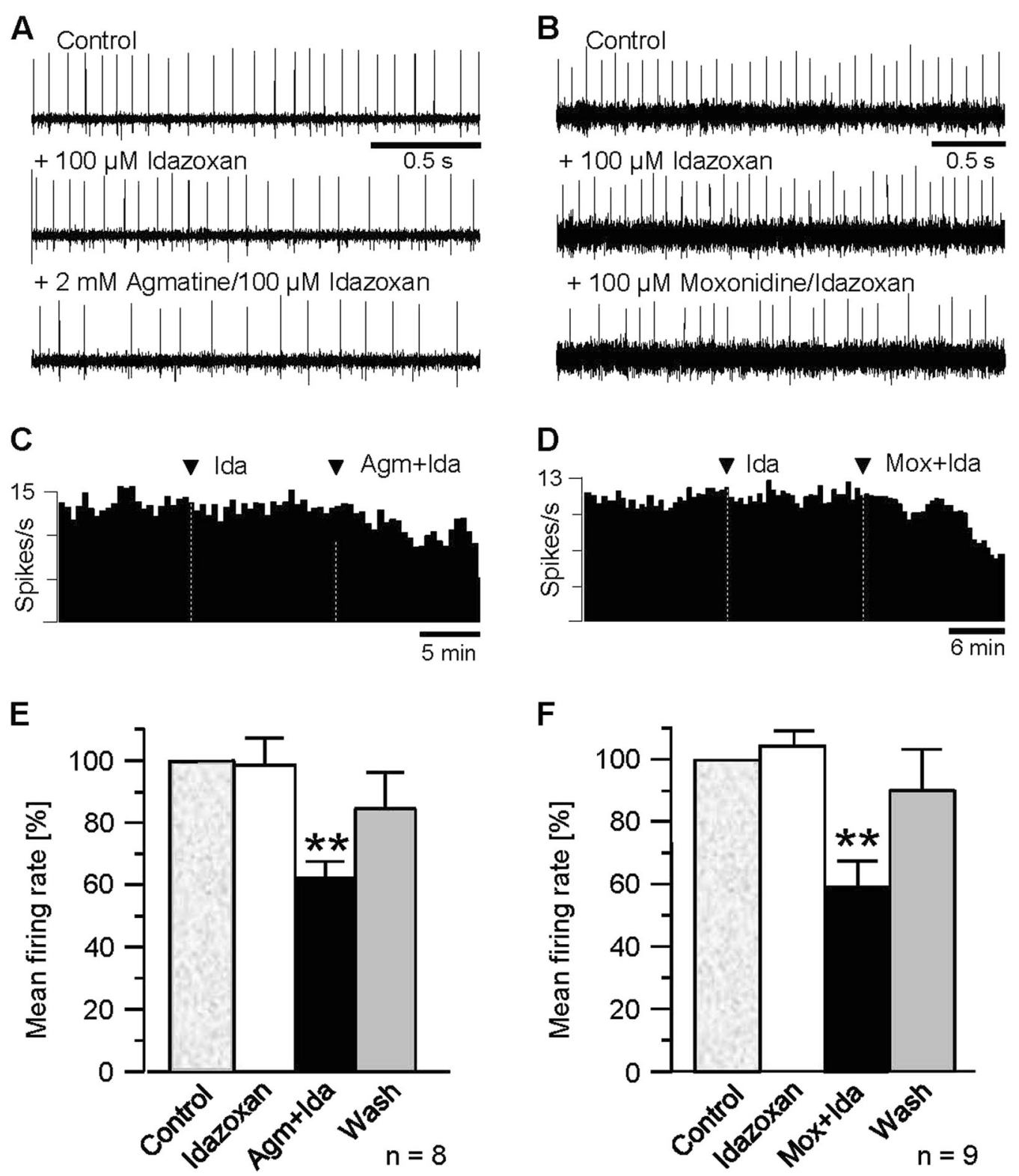

Fig. 4 Agmatine- and moxonidine-mediated suppression of spontaneous discharge of MHb neurons is not altered by idazoxan, an 12 -like imidazoline receptor antagonist. a Representative recordings from a MHb neuron in a slice under control conditions (top trace), with idazoxan (middle trace) and upon idazoxan co-applied with agmatine (bottom trace). b Single-unit recordings from another slice under control conditions (top trace), with idazoxan (middle trace) and upon idazoxan co-applied with moxonidine (bottom trace). $\mathbf{c}$ and $\mathbf{d}$ Rate histograms (bin widths $30 \mathrm{~s}$ ) obtained from the recordings shown $a$ and $b$, illustrating the responses with idazoxan alone and following co-application of the 12 -receptor antagonist with agmatine and moxonidine, respectively. Arrow heads indicate the onsets of the respective application of the perfusion compounds. e and $\mathbf{f}$ Bar graphs summarizing the results of the experiments on idazoxan acting indicating the absence of any impact on both, agmatine- $(\mathbf{e}, n=8)$ and moxonidine- $(\mathbf{f}, n=9)$ mediated suppression of action potential firing in the MHb. Normalized data are plotted as mean firing rate \pm S.E.M. Asterisks indicate a significance level of $P \leq 0.05$ each

observation is in line with earlier investigations showing that (i) agmatine is about 30-fold selective for I1-, relative to $\alpha 2$-adrenoceptors ${ }^{54}$ and (ii) the high affinity component of platelet I1-binding sites displayed for agmatine a 800 - to 5000 -fold selectivity over the different types of $\alpha 2$-adrenoceptors ${ }^{55}$.

\section{Expression of the agmatinergic system in the MHb}

The presence of agmatine in the neurons of the MHb has previously been shown ${ }^{56}$. However, the expression of agmatinase, one of the enzymes capable of inactivating agmatine in the brain $^{24}$, was considered to reveal putative target areas of this neurotransmitter/neuromodulator in 

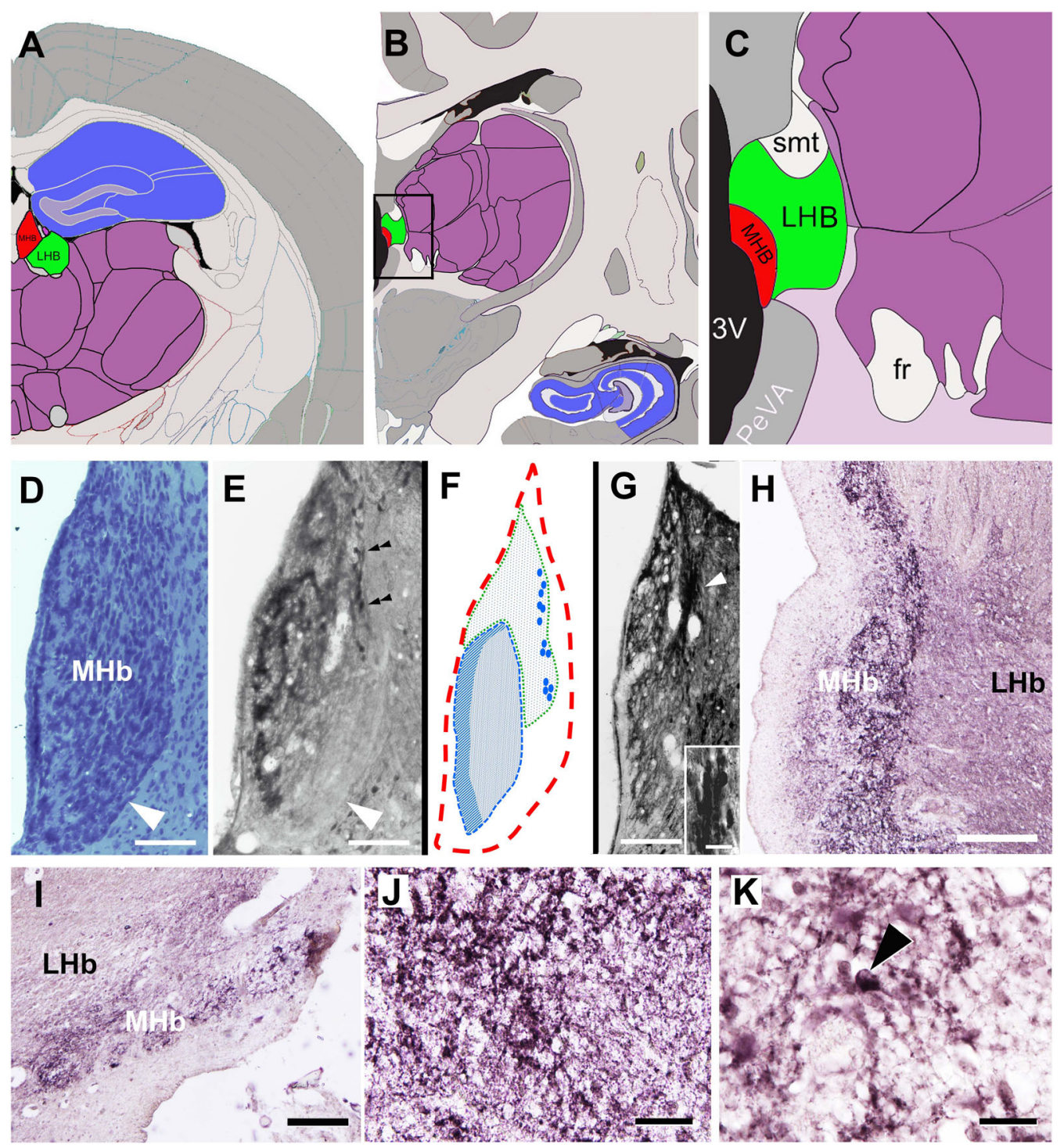

Fig. 5 Agmatinase in the $\mathbf{M H} \mathbf{b}$. a Allen adult mouse brain reference atlas. $\mathbf{b}$ and $\mathbf{c}$ Allen adult human brain reference atlas ${ }^{100}$. Compared to the rodent $\mathrm{MHb}$ (a, shown in red), the human $\mathrm{MHb}(\mathbf{b}, \mathbf{c})$ is located in a similar position, lining the lateral wall of the third ventricle, directly attached to the thalamus (purple). The relative position to the hippocampus (blue) is different due to the neocortical development in human brain. Image credit: Allen Institute (colors were modified). In cresyl violet-stained sections (d), the rat $\mathrm{MHb}$ appears relatively homogeneous and densely populated with neurons. Note the sharp border along the lower half of the nucleus (arrowhead). Agmatinase-like immunoreactivity (e) is mainly prominent in the neuropil, unveiling a sub-compartmentalization of the nucleus (ventrolateral border is indicated by an arrowhead). In addition, a stretch of strongly labeled neurons is evident in the upper lateral half (double arrowheads). The overall topography of neuropil and cell labeling is schematically delineated (f). With labeling for calretinin ( $\mathbf{g})$, a similar population of neurons (arrowhead and inset) is evident. The human MHb (h-k) also displays a heterogeneous agmatinase labeling pattern in frontal (h) and sagittal (i) sections, suggesting a similar sub-compartmentalization. A dense meshwork of fibers and terminals (j) forms a band of immunoreactivity clearly separated from the ventricular wall. Intensely labeled cell bodies are also evident (arrowhead in $\mathbf{k}$ ). Scale bars $=100 \mu \mathrm{m}$ in $\mathbf{d}, \mathbf{e}, \mathbf{g} ; 20 \mu \mathrm{m}$ in inset in $\mathbf{g} ; 200 \mu \mathrm{m}$ in $\mathbf{h}, \mathbf{i} ; 50 \mu \mathrm{m}$ in $\mathbf{j}, \mathbf{k}$

more detail ${ }^{25}$. Agmatinase was not only shown to be strongly expressed in rat but also in human $\mathrm{MHb}^{25}$. Thus, it may be speculated that similar patterns of activity with spontaneous firing of action potentials may also exist in the human brain. To date, however, this has not been experimentally verified. The similar differential distribution of agmatinase-positive fibers and neurons in both rat and human supports the notion of functional similarities. The overall morphological appearance of the habenula is similar in rat and human brain (Fig. $5 \mathrm{a}-\mathrm{c}$ ). However, due to differential neocortical development, the relative position of the habenula with respect to the hippocampus is remarkably different. In the rat, agmatinase-like immunoreactivity was localized to the neuropil and a 
subpopulation of habenular neurons located in the upper lateral aspect of the MHb (Fig. $5 \mathrm{~d}$, e). The neuropil labeling varied in intensity in distinct $\mathrm{MHb}$ areas. Accordingly, two prominent areas were detected along the ventricular border (schematically depicted in Fig. 5f).

\section{Co-localization with calcium-binding proteins}

Calcium-binding proteins represent markers widely used to characterize neuronal populations ${ }^{57}$. When comparing agmatinase-like immunoreactivity with caldendrin (Fig. 5g), a calcium-binding protein which was previously reported to co-localize with agmatinase in other brain areas ${ }^{25}$, a similar stretch of immunopositive neurons was observed. Similar to the rat, the human MHb also displayed a prominent agmatinase-like immunoreactivity with distinctive subregions (Fig. 5h, k). The neuropil contained numerous labeled fibers and terminals (Fig. 5i). Intensely labeled cell bodies were also evident, but not as closely associated as in the rat (Fig. 5j).

In order to further characterize the neurochemical topography within the $\mathrm{MHb}$, we employed a number of neurochemical markers displaying differential labeling patterns in this area (see supplementary Fig. S3). Among these markers, both calretinin and calbindin showed a pattern similar to the agmatinase distribution (Fig. S3 J,K, $\mathrm{L})$. In addition to the $\mathrm{MHb}$, this similarity in the distribution of the two calcium-binding proteins and agmatinase also applied for the LHb. Interestingly, both, the main input and output systems of the MHb, the triangular septum and the IPN, respectively, also prominently express agmatinase, as well as calretinin (Fig. S1 G-L). In order to further verify the overlap in the expression of agmatinase, calretinin, and calbindin in the same population of neurons, we employed immunofluorescence double labeling (Fig. S2). In addition to a co-localization of agmatinase and calretinin (Fig. S2 C, D), both the colocalization of agmatinase and calbindin (Fig. S2 A,B) as well as of calretinin and calbindin (Fig. S2 E,F) were observed in individual neurons. The connectivity of the $\mathrm{MHb}$ was previously analyzed ${ }^{5,6,14}$. We re-evaluated this network with anterograde and retrograde labeling (see Fig. S4).

\section{Discussion}

In the epithalamus, the habenulae represent the relay station connecting limbic forebrain structures with midbrain diffuse neurotransmitter systems, including the dopaminergic and serotoninergic systems. Within this relay station, the $\mathrm{MHb}$ and the $\mathrm{LHb}$ form separate entities with regard to morphology, connectivity, and electrical activity. Both nuclei, however, consist of several subnuclei, indicating further complexity of the involved circuits. Despite this morphological and neurochemical heterogeneity, neurons within either the LHb on one hand and the MHb, on the other, are characterized by similar patterns of electrical activity. While lateral habenular neurons produce action potentials in burst mode upon activation, a significant fraction of $\mathrm{MHb}$ neurons spontaneously generates tonic trains of action potentials ${ }^{8,58}$. When compared with previous studies ${ }^{8,59}$, the mean frequency of action potential trains measured in this study, however, was obviously higher $[9.5 \mathrm{~Hz}(1-20 \mathrm{~Hz})$ as compared to $5.0 \mathrm{~Hz}\left(1-10 \mathrm{~Hz}\right.$; ref. $\left.^{8}\right)$ and $4.2 \mathrm{~Hz}(2-10 \mathrm{~Hz}$; ref. $\left.^{59}\right)$ ]. The latter study also revealed that cholinergic, but not peptidergic, neurons show spontaneous action potential firing.

With respect to neurotransmitter release, the dorsal component of the MHb was shown to express substance $\mathrm{P}^{60}$, while the ventral component accounts for acetylcholine release in the IPN ${ }^{61}$. In addition to acetylcholine and substance $\mathrm{P}$, glutamate is also released by $\mathrm{MHb}$ projection neurons in the IPN ${ }^{14}$. Glutamate, in addition to ATP, is also released in the MHb by axons arising from the triangular septum ${ }^{14}$. Furthermore, genetic ablation of $\mathrm{MHb}$ neurons led to a massive reduction of acetylcholine in the IPN and a variety of behavioral abnormalities ${ }^{62}$. Thus, any interference with cholinergic and glutamatergic signaling in the dorsal diencephalic conduction system can be expected to significantly influence the balance of limbic circuits. Agmatine is known to interact with both, cholinergic and glutamatergic, systems. It blocks exocytosis in chromaffin cells by blocking nicotinic acetylcholine receptor currents ${ }^{63}$ and is involved with nicotine $e^{64}$, morphine ${ }^{65}$, and ethanol ${ }^{66}$ withdrawal. With respect to glutamate receptors, agmatine has been shown to antagonize the NMDA subclass in a concentration- and voltage-dependent manner in the hippocampal neurons ${ }^{67}$. Hence, the aforementioned withdrawal syndromes may be related to glutamate signaling at NMDA-receptorcontaining synapses (reviewed in refs. ${ }^{24,68}$ ). In the present study, we show that agmatine attenuates the tonic firing of action potentials in the MHb. Since the IPN is the major target of the $\mathrm{MHb}$ and given that the IPN activity in turn decreases the midbrain dopamine release ${ }^{69}$, it can be concluded that agmatine may regulate the inhibitory effect of the habenula-interpeduncular pathway on the reward system. This idea is further supported by the fact that agmatine seemingly acts as an endogenous antidepressant ${ }^{70}$ and a malfunction of the reward system is a hallmark of depression ${ }^{71-73}$.

Since agmatine may interact with different receptor types, including $\alpha 2$-adrenergic and imidazoline receptors, we tested different agonists and antagonists in order to characterize the nature of the suppression of tonic activity in the MHb. Accordingly, the inhibitory effect is apparently mediated by activation of imidazoline receptors of the I1-subtype. Both imidazoline I1 and I2 receptor subtypes have been reported to be expressed in neurons and 
astrocytes $^{74}$. In the $\mathrm{MHb}$, an imidazoline receptor protein was immunocytochemically localized ${ }^{75}$. Also, [3H]-RS45041-190, a selective high-affinity radio ligand for I2 imidazoline receptors, intensely labeled the $\mathrm{MHb}^{76}$. Moreover, imidazoline I1 receptors (IRAS/nischarin; see: (C) 2017 Allen Institute for Brain Science. Allen Mouse Brain Atlas. Available from: http://mouse.brain-map.org/, ISH experiment 69134550, P56 mouse, section no. 18, accessed at 04/27/2018 12:50 pm) and imidazoline I2 receptors $^{77}$ have both been localized to the MHb by in situ hybridization. Furthermore, clonidine, an imidazoline and $\alpha 2$-adrenergic agonist ${ }^{78,79}$, was shown to attenuate increased brain glucose metabolism during naloxone-precipitated morphine withdrawal in the $\mathrm{MHb}^{80,81}$. Similarly, agmatine prevented the naloxoneprecipitated abstinence syndrome in morphine-dependent rats $^{65}$. Thus, a role for agmatine acting via imidazoline I1 receptors in addiction, as well as possibly in depression, may be hypothesized (reviewed in ref. $^{24}$ ). In support of our data, the involvement of I1 imidazoline receptors with the antidepressant-like action of agmatine in mouse models of depression has been elegantly demonstrated using different behavioral tests ${ }^{82}$. Interestingly, the mouse I1 receptor homolog IRAS/nischarin was found to be downregulated in the prefrontal cortex of postmortem brains from individuals with major depression who received antidepressant drug treatment ${ }^{83}$. In subcortical limbic structures, however, this may be different. In this context, the role of the MHb-IPN-pathway in addiction and mood regulation has been recently reviewed ${ }^{84}$.

With regard to the subnuclear organization of the $\mathrm{MHb}$, agmatinase-like immunoreactivity is found in a subpopulation of neurons in the dorsolateral aspect and diffusely throughout the neuropil of the nucleus, but most prominently in the ventromedial aspect (Fig. 5f). According to our data from retrograde tracing in the rat IPN (Fig. S4), the dorsal half of the MHb is apparently connected to the lateral IPN, which in turn also contains the most intense immunosignal for agmatinase within the IPN (Fig. S1l). On the other hand, the ventral half of the $\mathrm{MHb}$ is highly enriched with nicotinic acetylcholine receptors ${ }^{85}$. For comparison, other markers like L-enkephalin, NK-A, and calbindin (see supplemental figure 1) define areas within the $\mathrm{MHb}$ only partially overlapping with the peptidergic dorsal and the cholinergic ventral region. Thus, a revision of the originally morphologically defined subnuclei of the MHb may need a systematic effort in order to integrate all known data regarding putative functional subdomains. A recent transcriptomic-anatomic study supports the idea of the presence of novel subfields ${ }^{86}$.

The etiology of major depressive disorder is undoubtedly complex and several pathophysiological mechanisms have been intensely examined, including the monoamine hypothesis, the glutamate hypothesis, genetic factors, endocrine factors (notably the Hypothalamus-PituitaryAdrenal axis dysfunction), environmental stress factors, and immunologic factors (reviewed in refs. ${ }^{87,88}$ ). However, common therapies are frequently based on the interference with monoamine levels by using monoamine oxidase inhibitors and serotonin re-uptake inhibitors. Interestingly, a robust expression of the serotonin receptor $5 \mathrm{HT}-4$ was observed in the lower half of the MHb (5 hydroxytryptamine receptor 4; see: $\odot 2017$ Allen Institute for Brain Science. Allen Mouse Brain Atlas. Available from: http://mouse.brain-map.org/, ISH experiment 72119658, P56 mouse, section no. 29, accessed at 07/23/ 2018 12:43 pm). This expression pattern is at least partially overlapping with the most prominent labeling for agmatinase within the MHb. In concordance, in the hamster brain, a dense innervation of the MHb by $5-\mathrm{HT}$ IR fibers has been shown, in contrast to an only verysparse innervation from the dorsal and median raphe nuclei $^{89}$. Thus, it is tempting to speculate that therapy with serotonin re-uptake inhibitors may interfere with the agmatinergic system in this area. Noteworthy, also monoamine oxidase is robustly expressed in the lateral part of the MHb (MAO A; see: $\odot 2017$ Allen Institute for Brain Science. Allen Mouse Brain Atlas. Available from: http://mouse.brain-map.org/, ISH experiment 74750015, P56 mouse, section no. 27, accessed at 07/25/2018 $10: 15 \mathrm{pm}$ ) and may be inhibited by agmatine under certain conditions ${ }^{90}$. In addition to serotonin and norepinephrine, a diminished dopaminergic neurotransmission and an impaired cholinergic transmission are evidently involved in the pathophysiology of major depression and of addiction ${ }^{91,92}$. To this end, the habenula apparently acts as a central regulator of diffuse neurotransmitter systems. While the LHb modulates serotonin levels and norepinephrine release, the $\mathrm{MHb}$ regulates acetylcholine and dopamine levels ${ }^{93,94}$. Given that in congenitally helpless rats, an animal model for depression, an elevated metabolism of $64-71 \%$ in the habenula and of $25 \%$ in the interpeduncular nucleus (K, $\mathrm{L})$, were observed ${ }^{31}$, the habenular-interpeduncular axis seems to represent a promising target for the development of new therapeutic strategies. In this scenario, the results presented here suggest that the pharmacologic interference with the agmatinergic system may promise great potential in order to develop related strategies.

\section{Conclusion}

In summary, we conclude that our electrophysiological data support the idea that the agmatinergic system influences brain function in addiction, anxiety, and depression. Accordingly, the release of agmatine in the $\mathrm{MHb}$, acting on imidazoline I1 receptors, would lead to decreased excitation of the IPN and hence to an increase 
of dopaminergic function in the midbrain. Besides the relevance for depression, for more detailed information on the role of agmatine in addiction and anxiety, we refer to recent reviews ${ }^{24,68}$. Interestingly, anxiety increased the activity of neurons in the IPN ${ }^{95}$. This activation during nicotine withdrawal was mediated by increased corticotropin releasing factor receptor-1 expression and signaling, which in turn modulated glutamatergic input from the MHb. Thus, there is evidence that both agmatine and the MHb may play pivotal roles not only in depression but also in anxiety and addiction. Similar to the $\mathrm{LHb}$, the $\mathrm{MHb}$ function probably has to be expected to fall into several subsystems. The habenula on the whole likely represents a bottleneck in the subcortical emotional brain circuits. Consequently, deep brain stimulation in this area has undergone preclinical and clinical trials ${ }^{96}$ (reviewed in refs. ${ }^{97-99}$ ). Interference with the agmatinergic system, however, may offer a pharmacological alternative to surgical therapy. Currently, our electrophysiological experiments are limited to normal ("not depressed") experimental animals. In the future, it will be interesting to gain additional insight with similar experiments performed with brains derived from animal models for depression, like congenital helpless rats.

\section{Acknowledgements}

The authors gratefully acknowledge the expert technical assistance of Reinhard Lommel, Ina Wolter, Maren Schrölkamp, and Henrik Dobrowolny. We thank Dr. Michael Depew for carefully proofreading the manuscript.

\section{Author details}

${ }^{1}$ Charité - Universitätsmedizin Berlin, corporate member of Freie Universität Berlin, Humboldt-Universität zu Berlin, and Berlin Institute of Health, Institute of Vegetative Anatomy, Berlin, Germany. ${ }^{2}$ Charité - Universitätsmedizin Berlin, corporate member of Freie Universität Berlin, Humboldt-Universität zu Berlin, and Berlin Institute of Health, Klinik für Neurologie, Department of Experimental Neurology, Berlin, Germany. ${ }^{3}$ Department of Psychiatry and Psychotherapy, Medical Faculty, University of Magdeburg, Magdeburg, Germany

\section{Conflict of interest}

The authors declare that they have no conflict of interest.

\section{Publisher's note}

Springer Nature remains neutral with regard to jurisdictional claims in published maps and institutional affiliations.

Supplementary Information accompanies this paper at (https://doi.org/ 10.1038/s41398-018-0254-z).

Received: 14 May 2018 Revised: 2 August 2018 Accepted: 17 August 2018 Published online: 24 September 2018

\section{References}

1. Guglielmotti, V. \& Cristino, L. The interplay between the pineal complex and the habenular nuclei in lower vertebrates in the context of the evolution of cerebral asymmetry. Brain Res. Bull. 69, 475-488 (2006).

2. Hikosaka, O. The habenula: from stress evasion to value-based decisionmaking. Nat. Rev. Neurosci. 11, 503-513 (2010).
3. Proulx, C. D., Hikosaka, O. \& Malinow, R. Reward processing by the lateral habenula in normal and depressive behaviors. Nat. Neurosci. 17, 1146-1152 (2014).

4. Lecourtier, L. \& Kelly, P. H. A conductor hidden in the orchestra? Role of the habenular complex in monoamine transmission and cognition. Neurosci. Biobehav. Rev. 31, 658-672 (2007).

5. Herkenham, M. \& Nauta, W. J. Efferent connections of the habenular nuclei in the rat. J. Comp. Neurol. 187, 19-47 (1979).

6. Herkenham, M. \& Nauta, W. J. Afferent connections of the habenular nuclei in the rat. A horseradish peroxidase study, with a note on the fiber-ofpassage problem. J. Comp. Neurol. 173, 123-146 (1977).

7. Andres, K. H., von During, M. \& Veh, R. W. Subnuclear organization of the rat habenular complexes. J. Comp. Neurol. 407, 130-150 (1999).

8. Kim, U. \& Chang, S. Y. Dendritic morphology, local circuitry, and intrinsic electrophysiology of neurons in the rat medial and lateral habenular nuclei of the epithalamus. J. Comp. Neurol. 483, 236-250 (2005).

9. Viswanath, H., Carter, A. Q., Baldwin, P. R., Molfese, D. L. \& Salas, R. The medial habenula: still neglected. Front. Hum. Neurosci. 7, 931 (2013).

10. Klemm, W. R. Habenular and interpeduncularis nuclei: shared components in multiple-function networks. Med. Sci. Monit. 10, RA261-RA273 (2004).

11. Aizawa, H., Kobayashi, M., Tanaka, S., Fukai, T. \& Okamoto, H. Molecular characterization of the subnuclei in rat habenula. J. Comp. Neurol. 520, 4051-4066 (2012).

12. Lima, L. B. et al. Afferent and efferent connections of the interpeduncular nucleus with special reference to circuits involving the habenula and raphe nuclei. J. Comp. Neurol. 525, 2411-2442 (2017).

13. Wagner, F., Stroh, T. \& Veh, R. W. Correlating habenular subnuclei in rat and mouse by using topographic, morphological, and cytochemical criteria. J. Comp. Neurol. 522, 2650-2662 (2014).

14. Qin, C. \& Luo, M. Neurochemical phenotypes of the afferent and efferent projections of the mouse medial habenula. Neuroscience 161, 827-837 (2009).

15. Sheffield, E. B., Quick, M. W. \& Lester, R. A. Nicotinic acetylcholine receptor subunit mRNA expression and channel function in medial habenula neurons. Neuropharmacology 39, 2591-2603 (2000).

16. Durkin, M. M., Gunwaldsen, C. A., Borowsky, B., Jones, K. A. \& Branchek, T. A. An in situ hybridization study of the distribution of the GABA(B2) protein mRNA in the rat CNS. Brain Res. Mol. Brain Res. 71, 185-200 (1999).

17. Bischoff, $S$. et al. Spatial distribution of GABA(B)R1 receptor mRNA and binding sites in the rat brain. J. Comp. Neurol. 412, 1-16 (1999).

18. Molas, S., DeGroot, S. R., Zhao-Shea, R. \& Tapper, A. R. Anxiety and nicotine dependence: emerging role of the habenulo-interpeduncular axis. Trends Pharmacol. Sci. 38, 169-180 (2017).

19. Leslie, F. M., Mojica, C. Y. \& Reynaga, D. D. Nicotinic receptors in addiction pathways. Mol. Pharmacol. 83, 753-758 (2013).

20. Gorlich, A. et al. Pacemaking of midbrain habenular cholinergic neurons in nicotine withdrawal. Biochem. Pharmacol. 86, 1235-1235 (2013).

21. Kim, U. \& Chung, L. Y. Dual GABAergic synaptic response of fast excitation and slow inhibition in the medial habenula of rat epithalamus. J. Neurophysiol. 98, 1323-1332 (2007).

22. Wagner, F., Weiss, T. \& Veh, R. W. Electrophysiological properties of neurons and synapses in the lateral habenular complex (LHb). Pharmacol. Biochem. Behav. 162, 38-45 (2017).

23. Belin, M. F. et al. A radioautographic and immunocytochemical study of the GABA systems of the habenula complex in the rat. Neurochem. Int. 4 303-312 (1982).

24. Laube, G. \& Bernstein, H. G. Agmatine: multifunctional arginine metabolite and magic bullet in clinical neuroscience? Biochem. J. 474, 2619-2640 (2017).

25. Bernstein, H. G. et al. The agmatine-degrading enzyme agmatinase: a key to agmatine signaling in rat and human brain? Amino Acids 40, 453-465 (2011).

26. Bernstein, H.-G. et al. Agmatinase and human cationic amino acid transporter 1 in mood disorder: what's under the microscope? JNBS 1, 67-71 (2014).

27. Hsu, Y. W. et al. Role of the dorsal medial habenula in the regulation of voluntary activity, motor function, hedonic state, and primary reinforcement. J. Neurosci. 34, 11366-11384 (2014).

28. Hsu, Y. W. Morton, G. Guy, E. G., Wang, S. D. \& Turner, E. E. Dorsal medial habenula regulation of mood-related behaviors and primary reinforcement by tachykinin-expressing habenula neurons. eNeuro 3, 109-116 (2016).

29. Caldecott-Hazard, S., Mazziotta, J. \& Phelps, M. Cerebral correlates of depressed behavior in rats, visualized using 14C-2-deoxyglucose autoradiography. J. Neurosci. 8, 1951-1961 (1988). 
30. Amat, J. et al. The role of the habenular complex in the elevation of dorsal raphe nucleus serotonin and the changes in the behavioral responses produced by uncontrollable stress. Brain Res. 917, 118-126 (2001).

31. Shumake, J., Edwards, E. \& Gonzalez-Lima, F. Opposite metabolic changes in the habenula and ventral tegmental area of a genetic model of helpless behavior. Brain Res. 963, 274-281 (2003).

32. Gawali, N. B. et al. Agmatine attenuates chronic unpredictable mild stressinduced anxiety, depression-like behaviours and cognitive impairment by modulating nitrergic signalling pathway. Brain Res. 1663, 66-77 (2017).

33. Gong, Z. H. et al. Anxiolytic effect of agmatine in rats and mice. Eur. J. Pharmacol. 550, 112-116 (2006).

34. Lavinsky, D., Arteni, N. S. \& Netto, C. A. Agmatine induces anxiolysis in the elevated plus maze task in adult rats. Behav. Brain Res. 141, 19-24 (2003).

35. Yamaguchi, T., Danjo, T., Pastan, I., Hikida, T. \& Nakanishi, S. Distinct roles of segregated transmission of the septo-habenular pathway in anxiety and fear. Neuron 78, 537-544 (2013).

36. Ranft, K. et al. Evidence for structural abnormalities of the human habenular complex in affective disorders but not in schizophrenia. Psychol. Med. $\mathbf{4 0}$ 557-567 (2010).

37. Rolls, E. T. A non-reward attractor theory of depression. Neurosci. Biobehav. Rev. 68, 47-58 (2016).

38. Loonen, A. J., \& Ivanova, S. A. Commentary on "A non-reward attractor theory of depression": a proposal to include the habenula connection. Neurosci. Biobehav. Rev. 83, 736-741 (2017).

39. Owens, M. J. \& Nemeroff, C. B. Role of serotonin in the pathophysiology of depression: focus on the serotonin transporter. Clin. Chem. 40, 288-295 (1994).

40. Roiser, J. P. et al. The effects of tryptophan depletion on neural responses to emotional words in remitted depression. Biol. Psychiatry 66, 441-450 (2009).

41. Zomkowski, A. D. E. et al. Evidence for serotonin receptor subtypes involvement in agmatine antidepressant like-effect in the mouse forced swimming test. Brain Res. 1023, 253-263 (2004).

42. Krass, M., Wegener, G., Vasar, E. \& Volke, V. Antidepressant-like effect of agmatine is not mediated by serotonin. Behav. Brain Res. 188, 324-328 (2008)

43. Bernstein, H. G. et al. Regional and cellular distribution of neural visinin-like protein immunoreactivities (VILIP-1 and VILIP-3) in human brain. J. Neurocytol. 28, 655-662 (1999)

44. Krauss, M. et al. Cellular and subcellular rat brain spermidine synthase expression patterns suggest region-specific roles for polyamines, including cerebellar pre-synaptic function. J. Neurochem. 103, 679-693 (2007).

45. Arai, R., Jacobowitz, D. M. \& Nagatsu, I. Calretinin is differentially localized in magnocellular oxytocin neurons of the rat hypothalamus. A double-labeling immunofluorescence study. Brain Res. 735, 154-158 (1996).

46. Winsky, L., Isaacs, K. R. \& Jacobowitz, D. M. Calretinin mRNA and immunoreactivity in the medullary reticular formation of the rat: colocalization with glutamate receptors. Brain Res. 741, 123-133 (1996).

47. Celio, M. R., Baier, W., Scharer, L., de Viragh, P. A. \& Gerday, C. Monoclonal antibodies directed against the calcium binding protein parvalbumin. Cell Calcium 9, 81-86 (1988).

48. Celio, M. R. et al. Monoclonal antibodies directed against the calcium binding protein Calbindin D-28k. Cell Calcium 11, 599-602 (1990).

49. Bernard, R. \& Veh, R. W. Individual neurons in the rat lateral habenular complex project mostly to the dopaminergic ventral tegmental area or to the serotonergic raphe nuclei. J. Comp. Neurol. 520, 2545-2558 (2012).

50. Li, G. et al. Agmatine: an endogenous clonidine-displacing substance in the brain. Science 263, 966-969 (1994).

51. Doxey, J. C., Roach, A. G. \& Smith, C. F. Studies on RX 781094: a selective, potent and specific antagonist of alpha 2-adrenoceptors. Br. J. Pharmacol. 78 489-505 (1983).

52. Shannon, H. E. \& Lutz, E. A. Yohimbine produces antinociception in the formalin test in rats: involvement of serotonin(1A) receptors. Psychopharmacology (Berl.) 149, 93-97 (2000).

53. Tellez, S., Colpaert, F. \& Marien, M. The alpha 2-adrenoceptor antagonist, $(+)$-efaroxan, enhances acetylcholine release in the rat cortex in vivo. Eur. J. Pharmacol. 277, 113-116 (1995).

54. Ernsberger, P. et al. 11-imidazoline receptors. Definition, characterization, distribution, and transmembrane signaling. Ann. N Y Acad. Sci. 763, 22-42 (1995).

55. Piletz, J. E., Zhu, H. \& Chikkala, D. N. Comparison of ligand binding affinities at human 11 -imidazoline binding sites and the high affinity state of alpha-2 adrenoceptor subtypes. J. Pharmacol. Exp. Ther. 279, 694-702 (1996).
56. Otake, K. et al. Regional localization of agmatine in the rat brain: an immunocytochemical study. Brain Res. 787, 1-14 (1998).

57. Andressen, C., Blumcke, I. \& Celio, M. R. Calcium-binding proteins - selective markers of nerve-cells. Cell Tissue Res. 271, 181-208 (1993).

58. Chang, S. Y. \& Kim, U. lonic mechanism of long-lasting discharges of action Potentials triggered by membrane hyperpolarization in the medial lateral habenula. J. Neurosci. 24, 2172-2181 (2004).

59. Gorlich, A. et al. Reexposure to nicotine during withdrawal increases the pacemaking activity of cholinergic habenular neurons. Proc. Natl Acad. Sci. USA 110, 17077-17082 (2013).

60. Mroz, E. A., Brownstein, M. J. \& Leeman, S. E. Evidence for substance-P in habenulo-interpeduncular tract. Brain Res. 113, 597-599 (1976).

61. Grady, S. R. et al. Rodent habenulo-interpeduncular pathway expresses a large variety of uncommon nAChR subtypes, but only the alpha 3 beta $4^{*}$ and alpha 3 beta 3 beta $4^{*}$ subtypes mediate acetylcholine release. J. Neurosci. 29, 2272-2282 (2009).

62. Kobayashi, Y. et al. Genetic dissection of medial habenula-interpeduncular nucleus pathway function in mice. Front. Behav. Neurosci. 7, 17 (2013).

63. Santos, W. C. et al. Blockade by agmatine of catecholamine release from chromaffin cells is unrelated to imidazoline receptors. Eur. J. Pharmacol. 417, 99-109 (2001).

64. Kotagale, N. R., Chopde, C. T., Umekar, M. J. \& Taksande, B. G. Chronic agmatine treatment prevents behavioral manifestations of nicotine withdrawal in mice. Eur. J. Pharmacol. 754, 190-198 (2015).

65. Aricioglu-Kartal, F. \& Uzbay, I. T. Inhibitory effect of agmatine on naloxoneprecipitated abstinence syndrome in morphine dependent rats. Life Sci. 61, 1775-1781 (1997).

66. Uzbay, I. T., Yesilyurt, O., Celik, T., Ergun, H. \& Isimer, A. Effects of agmatine on ethanol withdrawal syndrome in rats. Behav. Brain Res. 107, 153-159 (2000).

67. Yang, X. C. \& Reis, D. J. Agmatine selectively blocks the N-methyl-D-aspartate subclass of glutamate receptor channels in rat hippocampal neurons. J. Pharmacol. Exp. Ther. 288, 544-549 (1999).

68. Uzbay, T. I. The pharmacological importance of agmatine in the brain. Neurosci. Biobehav. Rev. 36, 502-519 (2012)

69. Nishikawa, T., Fage, D. \& Scatton, B. Evidence for, and nature of, the tonic inhibitory influence of habenulointerpeduncular pathways upon cerebral dopaminergic transmission in the rat. Brain Res. 373, 324-336 (1986).

70. Zomkowski, A. D. et al. Agmatine produces antidepressant-like effects in two models of depression in mice. Neuroreport 13, 387-391 (2002).

71. Cardenas, L. et al. Brain reward system activity in major depression and comorbid nicotine dependence. J. Pharmacol. Exp. Ther. 302, 1265-1271 (2002).

72. Martin-Soelch, C. Is depression associated with dysfunction of the central reward system? Biochem. Soc. Trans. 37, 313-317 (2009).

73. Naranjo, C. A., Tremblay, L. K. \& Busto, U. E. The role of the brain reward system in depression. Prog. Neuropsychopharmacol. Biol. Psychiatry $\mathbf{2 5}$ 781-823 (2001).

74. Keller, B. \& Garcia-Sevilla, J. A. Immunodetection and subcellular distribution of imidazoline receptor proteins with three antibodies in mouse and human brains: effects of treatments with 1-1- and 1-2-imidazoline drugs. J. Psychopharmacol. 29, 996-1012 (2015).

75. Ruggiero, D. A., Regunathan, S., Wang, H., Milner, T. A. \& Reis, D. J. Immunocytochemical localization of an imidazoline receptor protein in the central nervous system. Brain Res. 780, 270-293 (1998).

76. MacKinnon, A. C., Redfern, W. S. \& Brown, C. M. [3H]-RS-45041-190: a selective high-affinity radioligand for 12 imidazoline receptors. Br. J. Pharmacol. 116, 1729-1736 (1995).

77. Siemian, J. N., Jia, S., Liu, J. F. Zhang, Y. \& Li, J. X. Neuroanatomical characterization of imidazoline 12 receptor agonist-induced antinociception. Eur. J. Neurosci. 47, 1087-1095 (2018).

78. Ernsberger, P., Meeley, M. P., Mann, J. J. \& Reis, D. J. Clonidine binds to imidazole binding-sites as well as alpha-2-adrenoceptors in the ventrolateral medulla. Eur. J. Pharmacol. 134, 1-13 (1987).

79. Reis, D. J. \& Piletz, J. E. The imidazoline receptor in control of blood pressure by clonidine and allied drugs. Am. J. Physiol. 273, R1569-R1571 (1997).

80. Kimes, A. S., Bell, J. A. \& London, E. D. Clonidine attenuates increased brain glucose-metabolism during naloxone-precipitated morphine-withdrawal. Neuroscience 34, 633-644 (1990).

81. Yesilyurt, O. \& Uzbay, I. T. Agmatine potentiates the analgesic effect of morphine by an alpha(2)-adrenoceptor-mediated mechanism in mice. Neuropsychopharmacology 25, 98-103 (2001). 
82. Chen, Z. D., Chen, W. Q. Wang, Z. Y., Cao, D. N., Wu, N. \& Li, J. Antidepressantlike action of agmatine in the acute and sub-acute mouse models of depression: a receptor mechanism study. Metab. Brain Dis. 33, 1721-1731 (2018).

83. Keller, B. \& Garcia-Sevilla, J. A. Dysregulation of IRAS/nischarin and other potential 11-imidazoline receptors in major depression postmortem brain: downregulation of basal contents by antidepressant drug treatments. J. Affect. Disord. 208, 646-652 (2017).

84. McLaughlin, I., Dani, J. A. \& De Biasi, M. The medial hahenula and interpeduncular nucleus circuitry is critical in addiction, anxiety, and mood regulation. J. Neurochem. 142, 130-143 (2017).

85. Shih, P. Y. et al. Differential expression and function of nicotinic acetylcholine receptors in subdivisions of medial habenula. J. Neurosci. 34, 9789-9802 (2014).

86. Wagner, F., French, L. \& Veh, R. W. Transcriptomic-anatomic analysis of the mouse habenula uncovers a high molecular heterogeneity among neurons in the lateral complex, while gene expression in the medial complex largely obeys subnuclear boundaries. Brain Struct. Funct. 221, 39-58 (2016).

87. Jesulola, E., Micalos, P. \& Baguley, I. J. Understanding the pathophysiology of depression: from monoamines to the neurogenesis hypothesis model - are we there yet? Behav. Brain Res. 341, 79-90 (2018).

88. Sanacora, G., Treccani, G. \& Popoli, M. Towards a glutamate hypothesis of depression: an emerging frontier of neuropsychopharmacology for mood disorders. Neuropharmacology 62, 63-77 (2012).

89. Morin, L. P. \& Meyer-Bernstein, E. L. The ascending serotonergic system in the hamster: comparison with projections of the dorsal and median raphe nuclei. Neuroscience $\mathbf{9 1}, 81-105$ (1999).

90. Mancinelli, L. et al. Inhibitory effects of agmatine on monoamine oxidase (MAO) activity: reconciling the discrepancies. EuroBiotech. J. 2, 121-127 (2018).
91. Dunlop, B. W. \& Nemeroff, C. B. The role of dopamine in the pathophysiology of depression. Arch. Gen. Psychiatry 64, 327-337 (2007).

92. Rahman, S. Targeting brain nicotinic acetylcholine receptors to treat major depression and co-morbid alcohol or nicotine addiction. CNS Neurol. Disord. Drug Targets 14, 647-653 (2015).

93. Nishikawa, T., Fage, D. \& Scatton, B. Evidence for, and nature of, the tonic inhibitory influence of habenulointerpeduncular pathways upon cerebral dopaminergic transmission in the rat. Brain Res. 373, 324-336 (1986).

94. Velasquez, K. M., Molfese, D. L. \& Salas, R. The role of the habenula in drug addiction. Front. Hum. Neurosci. 8, 174 . https://doi.org/10.3389/ fnhum.2014.00174.

95. Zhao-Shea, R. et al. Increased CRF signalling in a ventral tegmental areainterpeduncular nucleus-medial habenula circuit induces anxiety during nicotine withdrawal. Nat. Commun. 6, 6770 (2015).

96. Sartorius, A. et al. Psychomodulation by bilateral deep brain stimulation of the lateral habenula in a patient long-lasting, therapy-refractory major depression. Pharmacopsychiatry 42, 239-239 (2009).

97. Yadid, G., Gispan, I. \& Lax, E. Lateral habenula deep brain stimulation for personalized treatment of drug addiction. Front. Hum. Neurosci. 7, 806 (2013).

98. Torres-Sanchez, S., Perez-Caballero, L. \& Berrocoso, E. Cellular and molecular mechanisms triggered by Deep Brain Stimulation in depression: a preclinical and clinical approach. Prog. Neuropsychopharmacol. Biol. Psychiatry 73, 1-10 (2017).

99. Dandekar, M. P., Fenoy, A. J., Carvalho, A. F. Soares, J. C. \& Quevedo, J. Deep brain stimulation for treatment-resistant depression: an integrative review of preclinical and clinical findings and translational implications. Mol. Psychiatry 203, 143-151 (2018).

100. Ding, S. L. et al. Comprehensive cellular-resolution atlas of the adult human brain. J. Comp. Neurol. 524, 3127-3481 (2016). 